\title{
Jornalismo e escândalos políticos: o confronto entre o julgamento e a objetividade
}

\author{
Journalism and political scandals: the confrontation between judgment and \\ objectivity \\ Débora Sartori ${ }^{1}$ \\ (debora.sartori@hotmail.com) \\ Flávio Porcello ${ }^{2}$ \\ (flavio.porcello@ufrgs.br) \\ http://dx.doi.org/10.5216/cei.v16i2.27387
}

\section{Resumo}

O presente artigo tem a intenção de refletir sobre a objetividade como um valor a ser perseguido na atividade jornalística, além de ser um princípio de legitimação social. A discussão será feita a partir da perspectiva que vê a mídia como um ambiente propício para a proliferação de escândalos políticos, o que está ligado à ideia dos jornalistas como cães de guarda, portadores do papel social de denunciar os que cometem desvios morais. Esta postura, adotada especialmente em relação aos governantes, caracteriza, muitas vezes, a profissão como contrapoder. Mas, ao posicionar-se contra os políticos, o jornalismo não está negando a busca utópica pela objetividade? Por outro lado, esta busca não comporia a explicação para a proliferação de escândalos midiáticos? Embora pareçam conceitos contraditórios, entendemos que a objetividade e a ideia de vigias sociais fazem parte da identidade jornalística.

Palavras-chave: Jornalismo. Objetividade. Escândalos políticos. Contrapoder.

\begin{abstract}
This article intends to reflect on objectivity as a value to be pursued in journalistic activity, besides being a principle of social legitimacy. The discussion will be made from the perspective that sees the media as an environment conducive to the proliferation of political scandals, which is connected to the idea of journalists as watchdogs, watchmen social bearers of the social role of denouncing those who commit moral deviations . This approach, adopted especially in relation to the rulers, featuring often the profession as countervailing. But the position itself against politicians, journalism is not denying the utopian quest for objectivity? Furthermore, this search does not compose the explanation for the proliferation of media scandal? Although they seem contradictory concepts, we understand that objectivity and the idea of social watchmen are part of journalistic identity.
\end{abstract}

Keywords: Journalism. Objectivity. Political scandals. Countervailing.

\footnotetext{
${ }^{1}$ Mestranda em Comunicação e Informação pela Universidade Federal do Rio Grande do Sul. Bolsista Capes. Tem experiência em redações telejornalísticas, onde exerceu diversas funções, como produtora, repórter, apresentadora, editora e editora-chefe.

${ }^{2}$ Doutor em Comunicação Social (PUCRS).Professor do Programa de Pós-Graduação em Comunicação e Informação da

Universidade Federal do Rio Grande do Sul (PPGCOM/UFRGS).
}

Comun \& Inf, v. 16, n. 2, p. 40-52, jul./dez. 2013 


\section{Introdução}

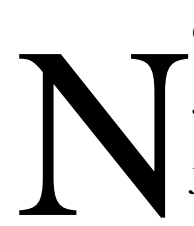

o artigo "Entre a Objetividade e a Vigilância: Contradições do Trabalho e da Identidade Jornalísticos", Fernanda Lima Lopes propõe confrontar as duas representações sobre o jornalismo: a de um profissional distante dos fatos - e que persegue a objetividade como valor fundamental -, e a do jornalismo "cão de guarda", atrelada à ideia de vigia social dos governos. O questionamento é se é possível ser um observador distante, mas adotar juízos de valor, como definir o que é certo e errado.

Neste sentido, a nossa proposta é avançar na discussão a partir do conceito de escândalo político, tomado de Thompson (2002), que identifica, a partir do surgimento da imprensa, uma nova constituição para os escândalos, que, por se desenrolarem em grande parte sob os holofotes da mídia, acabam sendo caracterizados por ela.

A aparente dicotomia que permeou o texto de Lopes e que, em alguma medida, também estará presente neste artigo, pode, na verdade, ser um dos fatores que contribuiu para a multiplicação de escândalos. Como trata-se de um trabalho ensaístico, sem análise de objeto empírico, o método utilizado será o da pesquisa bibliográfica, a partir de autores como Thompson (2002, 2012), Traquina (2005, 2008), Lopes (2007), Moretzsohn (2002, 2007), Schudson (2010), Tuchmann (1993), entre outros.

\section{A utopia da objetividade}

A teoria da Responsabilidade Social no Jornalismo surge a partir dos anos 50, nos Estados Unidos, fruto de um relatório da Comissão para a Liberdade de Imprensa. A teoria recomendava à imprensa não só relatar os fatos verdadeiramente, mas trazer a verdade sobre eles. Naquele contexto, é uma resposta ao atrelamento do jornalismo com o crescimento empresarial dos meios de comunicação. Portanto, a tensão com o campo comercial se instalava no confronto entre a deontologia do jornalista e a busca pelo lucro com a notícia. Seria a noção de responsabilidade social que permitiria ao jornalista preservar sua prática dos vínculos econômicos.

Mas, antes disso, segundo Moretzsohn (2002), alguns jornalistas norte-americanos já desenvolviam uma nova doutrina de trabalho, baseada na perspectiva de que o povo tem o direito às informações. Para a autora, esta prática referia-se, na verdade, ao fato de que o povo teria o direito de saber dos atos de governo. Daí, surge a ideia do jornalismo cão de guarda, representante do povo, vigia do poder. Expressões ligadas ao ideário de jornalismo romântico, de uma profissão

Comun \& Inf, v. 16, n. 2, p. 40-52, jul./dez. 2013 
diferenciada no sentido de estar socialmente legitimada no papel de fiscalizar as instituições políticas (PEREIRA, 2013).

Estas questões colocam a objetividade em uma posição central. Ser objetivo está ligado à fé de que seria possível reportar os acontecimentos de um ponto de vista a-político, como se os fatos pudessem falar por si. Na verdade, a matriz do pensamento objetivo é o que o separa da manipulação, em um período pós-guerra, de desconfiança em relação aos eventos (SCHUDSON, 2010).

Argumentar que os fatos falam por si, apesar do que haja de contradição lógica (pois obviamente os fatos não falam, quem fala é quem os identifica como importantes e os traduz como notícia), é uma forma de apresentá-los como neutros e, assim, inversamente, utilizá-los politicamente contra quem os quer silenciar (MORETZSOHN, 2002, p. 108).

É no pensamento científico da perspectiva construcionista de que as notícias ajudam a construir a realidade que defende-se a impossibilidade de uma linguagem neutra e de que os meios de comunicação estruturam a própria maneira de representar esta realidade. Isso não é o mesmo que ficção. Considerar as notícias como narrativas não significa negar-lhes o valor referencial de realidade, mas acreditar, assim como Tuchman (1993), que é uma realidade construída com sua própria validade interna.

Assim, a objetividade não seria o mesmo que neutralidade. É muito mais, conforme a autora, uma tentativa de não recorrer ao outro extremo, de que tudo é subjetivo. Para Tuchmam, assim como para Schudson, a noção de objetividade seria um mecanismo de proteção para os jornalistas. Em primeiro lugar, perpassa o fato de que os profissionais do campo reinvindicam para si a legitimidade de decidir sobre o caráter de noticiabilidade dos acontecimentos. Neste sentido é que a notícia constrói o acontecimento porque, como é um produto elaborado, não deixa de refletir alguns aspectos do processo de produção.

Além disso, a objetividade seria utilizada mais como um ritual estratégico, a fim de atender à racionalidade industrial e proteger os jornalistas de possíveis sanções e ameaças, como o cumprimento de prazos, críticas, processos judiciais. A necessidade de dominar o acontecimento e enquadrá-lo em um sistema um pouco mais previsível é uma das principais funções da mídia, e justamente neste processo de construção social da realidade é que as rotinas de informação desempenham papel fundamental. (ALSINA, 2009).

Entre as estratégias utilizadas por jornalistas para garantir a objetividade na narração e, de alguma maneira, proteger-se de críticas e censura, está o uso de aspas. Assim, o texto fica colocado como se estivesse sendo dito por outra pessoa, o que pressupõe o distanciamento do jornalista. A

Comun \& Inf, v. 16, n. 2, p. 40-52, jul./dez. 2013 
recorrente orientação de que o jornalista tem que ouvir os dois lados, portanto, faria parte, também, desta gama de procedimentos formais utilizados como rituais estratégicos. É uma atitude que busca equilibrar uma realidade que nunca é equilibrada (MORETZSOHN, 2002).

Outro procedimento que está presente neste processo é estruturação da informação de maneira adequada, de forma que, em primeiro lugar, são apresentados os fatos essenciais. Técnicas como o lead e a pirâmide invertida são muito usadas, em que os textos geralmente começam respondendo às perguntas "O quê? Quem? Quando? Onde? Como? Por quê?”, para só depois aprofundar a informação.

Um terceiro procedimento apontado por Tuchman é o que dá conta da separação entre informação e opinião e fatos e comentários. A crítica a esta visão, entretanto, afirma que a separação entre notícia e comentário seria nada mais do que uma divisão entre tipos de texto, um com uma estrutura mais argumentativa e outro com uma estrutura mais narrativa (CHAPARRO, 1994). O discurso da objetividade, portanto, está concentrado nos fatos, sem levar em consideração que os fatos precisam ser interpretados (ALSINA, 2009). É, de alguma maneira, uma utopia, um valor-limite a ser alcançado.

Entretanto, aqui no Brasil, este valor, importado da imprensa norte-americana, só ganhou força nas redações, por volta de década de 50, em função de todo um contexto propício (LOPES, 2007). A adoção de novas práticas ia enfraquecendo a maneira como se fazia jornalismo até então. Os textos longos, com linguagem rebuscada, foram sendo substituídos por textos mais objetivos. "Mudanças de ordem gráfica, tais como padronização nos títulos, uso de boxes e distribuição mais hierarquizada dos assuntos pelas páginas também foram adotadas, dando aos jornais uma nova “cara"” (LOPES, 2007, pg 6). A autora destaca, ainda, que foi a partir deste período que surgiram os primeiros manuais de redação e as técnicas de lead e pirâmide invertida passam a virar um padrão nos textos informativos.

\section{Jornalismo e escândalos políticos}

Ao estudar o escândalo político, Thompson (2002) se preocupou em entender os motivos da proliferação de casos na mídia. Para o autor, este fato pode estar ligado ao processo de desenvolvimento da imprensa. Antes, porém, é preciso esclarecer o conceito de escândalo político.

Comun \& Inf, v. 16, n. 2, p. 40-52, jul./dez. 2013 
Com o desenvolvimento da mídia, surgiu uma nova forma de interação entre os indivíduos ${ }^{3}$, que o pesquisador chama de "quase-interação mediada", ou seja, as relações sociais estabelecidas pelos meios de comunicação de massa. Dissemina-se através do espaço e do tempo e as formas simbólicas são produzidas para um número indefinido de receptores em potencial. O grau de reciprocidade é menor.

Ela é uma situação estruturada na qual alguns indivíduos se ocupam principalmente na produção de formas simbólicas para outros que não estão fisicamente presentes, enquanto estes se ocupam em receber formas simbólicas produzidas por outros a quem eles não podem responder, mas com quem podem criar laços de amizade, afeto e lealdade. (THOMPSON, 2012, p. 122)

No caso da quase-interação mediada, a capacidade técnica permitiu à televisão utilizar grande quantidade de deixas simbólicas, o que, em certo sentido, a aproxima da interação face a face. Por outro lado, possui um campo de visão diferente e direciona a visão do destinatário, porque é na instância de produção que são escolhidas as imagens e os enquadramentos que serão veiculados. De qualquer maneira, recursos visuais e auditivos criam, na televisão, um tipo de intimidade impossível a outros meios, como rádio, jornal e internet. Neste sentido, ao pensarmos em atores do campo político, podemos afirmar que questões relativas à aparência visual passaram a ser relevantes na administração da imagem pública.

A distinção entre público e privado, que tem origens na Grécia Clássica e no início do desenvolvimento do direito romano ganha, a partir do tipo de interação criada pelos meios de comunicação de massa, novos contornos na sociedade moderna. A dicotomia é assim definida por Thompson (2012):

Público, neste sentido é o que é visível ou observável, o que é realizado na frente de espectadores, o que está aberto para que todos os muitos vejam ou ouçam. Privado é, ao contrário, o que se esconde da vista dos outros, o que é dito ou feito em privacidade ou segredo ou entre um círculo restrito de pessoas. Neste sentido, a dicotomia tem a ver com publicidade versus privacidade, com abertura versus segredo, com visibilidade versus invisibilidade. Um ato público é um ato visível, realizado abertamente para que qualquer um possa ver; um ato privado é um ato invisível, realizado secretamente atrás de portas fechadas (p. 165).

O tipo de visibilidade criado pela mídia, portanto, alterou a noção de publicidade de um indivíduo em um evento como acontecia antes do advento da imprensa. Para um acontecimento

\footnotetext{
${ }^{3}$ Sem a presença dos meios de comunicação de massa, os indivíduos podem ter dois tipos de interação: face a face e mediada. A interação face a face é aquela que acontece em um contexto de copresença, quando os participantes estão no mesmo referencial de espaço e tempo e que implica em ida e volta do fluxo de informação. Neste tipo de interação, geralmente empregam-se deixas simbólicas, que podem ser gestos, entonações de voz, gestual, entre outros, usadas para aumentar a compreensão da mensagem. Já as interações mediadas exigem o uso de um meio técnico, permitem que os indivíduos estejam em contexto espaciais e temporais diferentes, mas reduzem as possibilidade de uso de deixas simbólicas.
}

Comun \& Inf, v. 16, n. 2, p. 40-52, jul./dez. 2013 
tornar-se público, dependia de um contexto de copresença. Os meios de comunicação de massa alteram essa lógica ao separar instância de produção e de recepção. Dirigem-se a um público espectador sem lugar.

Assim, para os atores que atuam no campo político, os meios de comunicação são o espaço público onde a visibilidade adquire repercussão.

A mídia se torna a arena central onde essa luta por poder simbólico é travada. Sendo a mídia o meio mais importante pelo qual os líderes políticos se relacionam com os cidadãos comuns, ela se torna assim o meio principal através do qual os líderes políticos acumulam capital simbólico no campo político mais amplo. Através do contínuo gerenciamento da visibilidade e da apresentação cuidadosa de si mesmos, os líderes políticos usam a mídia para construir um estoque de capital simbólico diante do eleitorado: e esse fato ao propiciar a eles, por sua vez, uma base de apoio popular, lhes dá poder no subcampo político. (THOMPSON, 2002, p. 139).

É claro que a disputa por visibilidade não depende apenas do jornalismo ou da comunicação midiática. Mas é neste ambiente em que a maneira como o político será mostrado não pode ser totalmente administrada. Ao mesmo tempo que pode reforçar a imagem que o indivíduo quer projetar, também pode construí-la de maneira totalmente diversa da pretendida. Para Weber (2009), o jornalismo:

É o espaço que vigia, critica e expõe ações e informações geradas por políticos, partidos e instituições do campo político. Mesmo estabelecendo pactos econômicos e ideológicos com determinadas instituições e sujeitos políticos, é nesse ambiente que prevalece a credibilidade. A instância que julga e tem o poder de propiciar visibilidade. (p. 87).

Um ambiente de maior visibilidade, como o midiático, aumenta as chances de que atividades executadas privadamente ou para um grupo restrito de pessoas sejam manifestadas na esfera pública. É o que Thompson (2002) chama de "escândalo midiático". Escândalo ao se referir a ações que envolvem, principalmente, a transgressão de valores, normas ou códigos morais. Midiático porque caracterizam aqueles acontecimentos que se desenrolam, pelo menos em parte, através da mídia. Os escândalos midiáticos, portanto, têm uma publicidade modelada pelas características de interação da mídia.

Thompson apropria-se dos conceitos de região frontal e região de fundos, do sociólogo Erving Goffman, para explicar como o vazamento de informações de uma região para outra podem caracterizar um escândalo. Toda a ação de um indivíduo acontece dentro de um referencial interativo, composto por convenções, pressupostos e características físicas do local. O indivíduo vai tentar adaptar seu comportamento a este referencial com o objetivo de tentar passar uma imagem de si próprio compatível com a impressão que deseja passar. Este referencial de ação acontece na

Comun \& Inf, v. 16, n. 2, p. 40-52, jul./dez. 2013 
região frontal. As ações que podem contradizer o que a pessoa quer mostrar são deixadas para as regiões de fundo, onde diminuem os mecanismos de autocontrole.

Com a mídia, pode haver o vazamento de atitudes da zona de fundos para a zona frontal. Se elas transgredirem certos valores, normas ou códigos morais, podem tornar-se escândalos midiáticos. Assim, as ações situadas no centro do escândalo ganham uma visibilidade que, de outro modo, não teriam. Portanto, o caráter midiático do escândalo aumenta suas proporções ao envolver indivíduos localizados em diferentes locais espaçotemporais. Para caracterizar-se como político, o escândalo precisa envolver indivíduos ou ações com impacto dentro do próprio campo. “É o campo político que caracteriza um escândalo político como político; ele fornece o contexto para o escândalo e configura seu padrão de desenvolvimento." (THOMPSON, 2002, p. 129).

O escândalo como acontecimento midiático nasceu no século XIX, mas se consolidou no século XX, através de duas vertentes, conforme Thompson. Uma está ligada ao crescimento e circulação da imprensa de massa. Os jornais, que começavam a se organizar em grandes empresas e buscar lucros a baixos custos para os leitores. Com isso, a disputa pela demarcação de posições e por fatias de mercado tornou-se mais acirrada. Dividiu-se, então, a imprensa mais ligada a critérios de objetividade, focada em informar, daquela de grande circulação, que priorizava o entretenimento.

Outra explicação é a consolidação da profissão do jornalismo, especialmente do jornalismo investigativo. Traquina (2005) aponta, entre as principais características do jornalismo contemporâneo, a constituição de uma cultura profissional compartilhada e um modo específico de ver o mundo que privilegia posições bipolares. No caso do jornalismo político, as ações de seleção e organização dos acontecimentos para dar sentido à realidade política podem ajudar a orientar as interpretações sobre este campo.

Neste sentido, o jornalismo se legitima como posição de oposição. Ou seja, o jornalista se firma com a função de buscar atos ocultos, principalmente em relação aos governos. A imprensa ocuparia, neste sentido, um papel de fiscalizador do Poder Público. Uma ideia ligada ao resguardo dos valores morais, da ética e do interesse público, além de reforçar a imagem de independência em relação aos poderes constituídos. Assim, ganha credibilidade e, acumulando recursos, assegura seu lugar no exercício do poder simbólico na sociedade. O jornalismo, portanto, baseia seu poder na ideia de representação do mundo e do interesse do público, um saber reconhecido como contrapoder (TRAQUINA, 2005).

O escândalo político atenderia às duas frentes, seja do ponto de vista econômico, pensando em uma mídia que obtém lucro com a venda de bens simbólicos - a notícia - ou do jornalismo 
guardião dos interesses públicos. Naquele, por serem histórias que se prestam bem à dramatização, principalmente por não terem um fim totalmente previsível. Neste, por assegurarem a legitimação da função fiscalizadora do campo.

Por possuir característica sequiencial, em que uma fase é seguida da outra ${ }^{4}$, os escândalos políticos podem atrair o interesse das pessoas. Com um fim incerto, "alentam a especulação e, como uma boa novela, eles constantemente testam a capacidade dos leitores e espectadores de avaliar a veracidade dos protagonistas, imaginar a trama, predizer seu resultado" (THOMPSON, 2002, p. 103). Assim, pode-se dizer que este tipo de acontecimento atende tanto ao jornalismo focado nas formas populares de histórias quanto àquele mais interessado em reunir e divulgar fatos.

A credibilidade, como um dos cânones do jornalismo moderno, é o principal capital simbólico da atividade (BERGER, 1998). Portanto, é preciso reforçar, a todo o momento, a crença neste poder. A tensão na constante necessidade de legitimação como campo de credibilidade pode ser uma explicação para a quantidade de escândalos políticos que se proliferam na mídia.

A credibilidade é construída no interior do jornal assim como um rótulo ou uma marca que deve se afirmar, sem, no entanto, nomear-se como tal. Credibilidade tem a ver com persuasão pois, no diálogo com o leitor, valem os 'efeitos de verdade', que são cuidadosamente construídos para servirem de comprovação, através de argumentos de autoridade, testemunhas e provas. (BERGER, 1998, p. 21-22)

Esta noção de credibilidade, no entanto, ativa o sentido de relação com o público, leva em consideração as interações do jornalismo com a audiência (ALSINA, 2009). Isto significa dizer que a construção da realidade se dá no processo de produção, circulação e reconhecimento. É uma perspectiva que, em certo grau, confere poder a este público. Primeiro, porque precisa legitimar socialmente a atividade jornalística. E, segundo, porque é parte integrante do processo de construção de sentido.

Mas esta relação de enredamento entre as pontas estabelece-se através de um contrato firmado entre as partes: o contrato pragmático fiduciário social e historicamente definido, baseado "em atitudes epistêmicas coletivas, que foram se compondo através da implantação do uso social da mídia como transmissores da realidade social de importância pública” (ALSINA, 2009, p. 47).

\footnotetext{
${ }^{4}$ Thompson define 4 fases para o escândalo. A fase pré-escândalo começa com a revelação da transgressão. A fase do escândalo propriamente dita caracteriza-se pela divulgação pública de uma ação, em que afirmações e contra-afirmações estão no foco. A mídia tem, neste momento, papel central. A fase do clímax ou desenlace é quando o escândalo atinge o estágio crítico e pode culminar com um julgamento ou indiciamento. A última fase é a das consequiências, quando o calor dos acontecimentos passou e a reflexão sobre as implicações ganham espaço, especialmente na mídia.
}

Comun \& Inf, v. 16, n. 2, p. 40-52, jul./dez. 2013 
Significa dizer que, nesta relação comunicativa, são firmados contratos para que o destinatário faça o uso adequado, do ponto de vista do emissor, daquela mensagem.

Assim, é preciso pensar na utilidade da informação jornalística, que é a de informar. Para que isso seja efetivo, quem recebe esta informação deve crer que aquele fato aconteceu daquele jeito que está sendo mostrado. Então, para cumprir sua principal função, a de fazer saber, o jornalismo deve ser acreditado como tal pela audiência. Nos "termos" do contrato, portanto, o que está previsto é que o público acredite que o que se diz é verdade, ao mesmo tempo em que se estabelece uma relação de confiança sobre o discurso informativo. Uma vez instaurada a desconfiança de que a notícia não se refere a fatos reais, ou que não retrata os acontecimentos como se deram, de alguma maneira, o contrato se quebra e a informação jornalística perde a utilidade. Instala-se um problema de credibilidade, que seria o principal capital simbólico do jornalismo.

Lutar pela ideia de credibilidade, portanto, é manter um capital que alimenta o poder social da profissão. Assim, investigar os atos ocultos do governo tem sido o alicerce sobre o qual se construiu a atividade jornalística. A imprensa ocuparia uma instância de fiscalização do Poder Público, como uma forma civil de poder, delegada pela sociedade e pelos cidadãos, dando visibilidade à coisa pública (MARTINS, 2002). Sob o aspecto da fiscalização, faz sentido observar como a cobertura política parte, a priori, da desconfiança em relação aos governos. Portanto, ao assumir o papel de porta-voz do interesse público, colocado em oposição ao poder dos governos, o jornalismo acaba por reforçar a sua credibilidade e, com isso, assegura, também, seu papel de poder dentro da sociedade.

Entretanto, este papel de porta-voz social está ligado à ideia de valores morais, pois, ao fiscalizar desvios cometidos no poder governamental, de alguma maneira, o jornalismo reforça o que é moralmente aceito. Esta noção parte da perspectiva de uma sociedade supostamente consensual. É o que Hall et al. (1993) chamam de mapas culturais, ou seja, alguns conhecimentos partilhados em uma sociedade. Neste sentido, os jornalistas interpretariam os fatos de acordo com estes esquemas de significação.

E estes esquemas são percebidos através de um processo de reiteração. As mesmas histórias são contadas todos os dias, mas com personagens e circunstâncias diferentes. São singularidades carregadas de sentidos universais: "O singular carrega o vetor da universalidade, ainda que esse universal não esteja explícito. Aquilo que faz o homem pertencer à sua espécie é o comportamento universal do imaginário". (BENETTI, 2009, p. 286). 
Para Motta (2002), consideradas como sistemas simbólicos, as notícias delineiam o bem e o mal, o que pode e o que não pode: "Interpretadas simbolicamente, as notícias se revelam como estórias, se mostram como fábulas da vida moderna" (p. 7). São, ao mesmo tempo, o registro da história, mas, também, impregnadas de conflitos humanos. Assim, basear-se em questões gerais, de ordem moral, que seriam aceitas por todos, significa que o compromisso com estes valores sociais não é uma questão de juízo de valor, mas de bom senso (MORETZSOHN, 2002).

Assim, retoma-se a pergunta que originou este artigo: é possível fazer um jornalismo que se pretende objetivo, mas que tornou-se um ambiente propício para a proliferação de escândalos políticos, uma vez que uma cobertura do tipo denúncia abarca noções de juízo de valor, de separação entre o bem e o mal? Pensando que o jornalismo que denuncia escândalos de natureza política exerce peso nas características que configuram o jornalismo, Lopes defende que as duas representações, aparentemente contraditórias, estão contidas na identidade da profissão.

Entretanto, a reflexão que propomos é como o conceito de escândalo midiático, especialmente aquele que envolve o campo político, portanto denominado de escândalo político, nasce de atitudes consideradas transgressões morais. E, em alguma medida, ao desenrolar-se através da imprensa, é moldado por características próprias dela, como a separação entre tempo e espaço, o que acaba por carregar estes fatos a outras dimensões e contextos diferentes daqueles em que aconteceram. Isso, de certa maneira, torna difuso o limite entre público e privado.

Neste sentido, entendemos, assim como Lopes, que, tanto a ideia ligada ao jornalismo sentinela como aquela que prega a objetividade e distanciamento dos fatos constituem a profissão. Mas, são as características desta atividade e a imprensa no sentido mais amplo, como o meio através do qual ela se materializa, que acabam moldando um tipo de escândalo político que só se desenrola, desta forma, através dela. Denunciar transgressões morais, portanto, dependem de juízo de valor, mais especificamente daqueles valores considerados supostamente consensuais. E este tipo de escândalo, quando acontece no campo político, integra, necessariamente, as manchetes porque fazem parte do tipo de assunto que, historicamente, legitimou socialmente o jornalismo.

Mas, mais do que isso, ao transformar o escândalo político em um escândalo midiático, no sentido de que os fatos se desenrolam sob os holofotes midiáticos, o jornalismo reveste-se de um papel capaz de atribuir-lhe o poder de representar, através de manchetes sucessivas por dias, semanas e até meses consecutivos, que tipo de comportamento deve ser tomado como bem ou como mal. 


\section{Considerações Finais}

Neste artigo propomos ampliar a discussão proposta por Lopes (2007) sobre a aparente contradição entre dois mitos que constituem a identidade jornalística. A primeira dá conta da ideia de jornalismo como contrapoder, daquele grupo legitimado socialmente para fiscalizar as possíveis transgressões nas ações dos poderes, especialmente no caso dos políticos. A segunda visão é aquele que prega a objetividade como um valor máximo a ser alcançado, baseada na noção de distanciamento dos acontecimentos e de que os fatos falam por si.

A partir do conceito de escândalo político, tomado de Thompson (2002), refletimos sobre como escândalos que acontecem no campo político e que se desenrolam sob os holofotes midiáticos podem, de alguma maneira, ser moldados por características da imprensa, mas também fazem parte da identidade que historicamente constituiu a profissão.

As duas representações podem ser abarcadas pelo jornalismo. Entretanto, a nossa intenção foi ampliar esta conclusão e discutir como, na verdade, a proliferação de escândalos políticos no jornalismo pode demonstrar como a profissão tenta legitimar-se socialmente, mantendo o capital conquistado através da credibilidade e vestindo-se de um papel que, em alguma medida, confere o poder de julgar, de dizer o que é o bem e o que é o mal.

Artigo submetido em 19/11/2013 e aceito em 31/01/2014.

\section{Referências}

BENETTI, Márcia. Jornalismo e imaginário: o lugar do universal. In: KUNSCH, Dimas (Org.). Esfera pública, redes e jornalismo. São Paulo: E-papers, 2009.

BERGER, Christa. Campos em confronto: a terra e o texto. Porto Alegre: Editora da Universidade/UFRGS, 1998.

CHAPARRO, Manuel Carlos. Pragmática do jornalismo: buscas práticas para uma teoria da ação jornalística. São Paulo: Summus, 1994.

HALL, Stuart et al. A produção social das notícias: o "mugging" nos media. In: TRAQUINA, Nelson (Org.). Jornalismo: questões, teorias e estórias. Lisboa: Veja, 1993.

LOPES, Fernanda Lima. Entre a objetividade e a vigilância: contradições do trabalho e da identidade jornalísticos. Revista Ciberlegenda, Niterói, ano 9, n. 18, jul. 2007. Disponível em: <http://www.uff.br/ciberlegenda/artigo7_julho2007.html>. Acesso em: 18 jul. 2013.

MARTINS, L. Imprensa e Cidadania: possibilidades e contradições. In: MOTTA, L. G. Imprensa e Poder. Brasília: Editora UnB, 2002. p. 47-74.

Comun \& Inf, v. 16, n. 2, p. 40-52, jul./dez. 2013 
MORETZSOHN, Sylvia. Pensando contra os fatos: jornalismo e cotidiano: do senso comum ao senso crítico. Rio de Janeiro: Revan, 2007.

MORETZSOHN, Sylvia. Jornalismo em "tempo real": o fetiche da velocidade. Rio de Janeiro: Revan, 2002.

MOTTA, Luiz Gonzaga. Explorações epistemológicas sobre uma antropologia da notícia. Revista Famecos, n. 19, dez. 2002b.

PEREIRA, Fábio Henrique. Da responsabilidade social ao jornalismo de mercado: o jornalismo como profissão. Disponível em: <http://www.bocc.ubi.pt/pag/pereira-fabio-responsabilidadejornalista.pdf>. Acesso em: 18 jul. 2013.

SCHUDSON, Michael. Descobrindo a notícia: uma história social dos jornais nos Estados Unidos. Petrópolis: Vozes, 2010.

THOMPSON, John B. O escândalo político. Petrópolis, RJ: Vozes, 2002.

THOMPSON, John B. A mídia e a modernidade: uma teoria social da mídia. Petrópolis, RJ:

Vozes, 2012.

TRAQUINA, Nelson. Teorias do jornalismo: porque as notícias são como são. Florianópolis: Insular, 2005.

TRAQUINA, Nelson. Teorias do jornalismo: a tribo jornalística: uma comunidade interpretativa transnacional. Florianópolis: Insular, 2008

TUCHMAN, Gaye. A objetividade como ritual estratégico: uma análise das noções de objetividade dos jornalistas. In: TRAQUINA, Nelson (Org.). Jornalismo: questões, teorias e "estórias". Lisboa: Veja, 1993.

WEBER, Maria Helena. O estatuto da imagem pública na disputa política. ECO-Pós, v. 12, n. 3, p. 79-94, set./dez. 2009. 